\title{
1987 REPORT ON NESTBOX PROJECT IN SOUTHWESTERN MANITOBA
}

\author{
MAMIE McCOWAN, 1415-8th Street, Brandon, Manitoba R7A $3 Z 6$
}

This report was submitted by the coordinating committee for The Friends of the Bluebirds, and was prepared by Hazel Patmore, Jean Horton, Barbara Robinson, David Barnes, Mamie McCowan, and the birdwatchers of Brandon.

The Friends of the Bluebirds of southwestern Manitoba, a volunteer group with a nestbox project coordinated from Brandon, are delighted to report an increase in both Mountain Bluebird and Eastern Bluebird nestings in 1987. A summary of reports received from 54 nestline operators is given in Table 1.

Some operators did not check boxes often enough to include second broods, so the actual total nestings of bluebirds would be greater than indicated. Other "Friends" maintained additional nestlines by cleaning and repairing boxes, but did not monitor nesting.
The reports contain interesting comments. Mildred and Jim Spear of Russell write: "Our bird numbers are up this year and an area about three miles square accounts for the increase. This is excellent bluebird country . . . in places boxes as close as 20 yards have nestings, one in particular, 7 boxes in less than a quarter mile had 6 Mountain Bluebird nestings and in the center of this was an Eastern Bluebird nesting; at times this makes me wonder about the territory each bird is supposed to have. Over the 15 years we have checked the lines we notice many changes in material used to build nests and in particular the Tree Swallow. Many now do not use the white feathers that cover the eggs - do they feel secure in their nesting boxes?"

Edie Evans of Rapid City comments: "I really feel the secret of our success was twinning. Have almost all boxes twinned

Table 1. NESTBOX USE IN SOUTHWESTERN MANITOBA, 1987

Species

Number of nestings

Mountain Bluebird

Eastern Bluebird

Unidentified bluebird

Mixed pair - Mountain male $x$ Eastern female

Tree Swallow

994

Wren

House Sparrow

Starling

Clay-colored Sparrow

Red Squirrel

Total number of boxes monitored

* nesting - a nest with at least 1 egg 
now." Twinning (placing two boxes close together, e.g. on adjacent fenceposts) will ease competition for boxes between bluebirds and swallows.

Red Squirrels created a problem in areas where White Spruce is common. Jean Horton reports: "Hardly any boxes that weren't chewed by red squirrels; 4 boxes contained large squirrel families and prevented bluebirds from nesting there." Hazel Patmore notes: "Red squirrels are becoming more troublesome. They have destroyed several boxes."

Many operators enlarged the entrance hole from $11 / 2^{\prime \prime}$ diameter to $1-9 / 16^{\prime \prime}$ or larger, to accommodate the Mountain Bluebird. The larger holes will help to offset shrinkage caused by swelling of wood in a wet season.

Moving boxes from marginal to good bluebird habitat was found to increase their use by bluebirds.

There were reports of dead bluebirds and Tree Swallows, mainly nestlings. Predators were blamed for some of the mortality. It is feared that blowfly infestations may be responsible for some deaths, and we plan to investigate this in coming seasons.

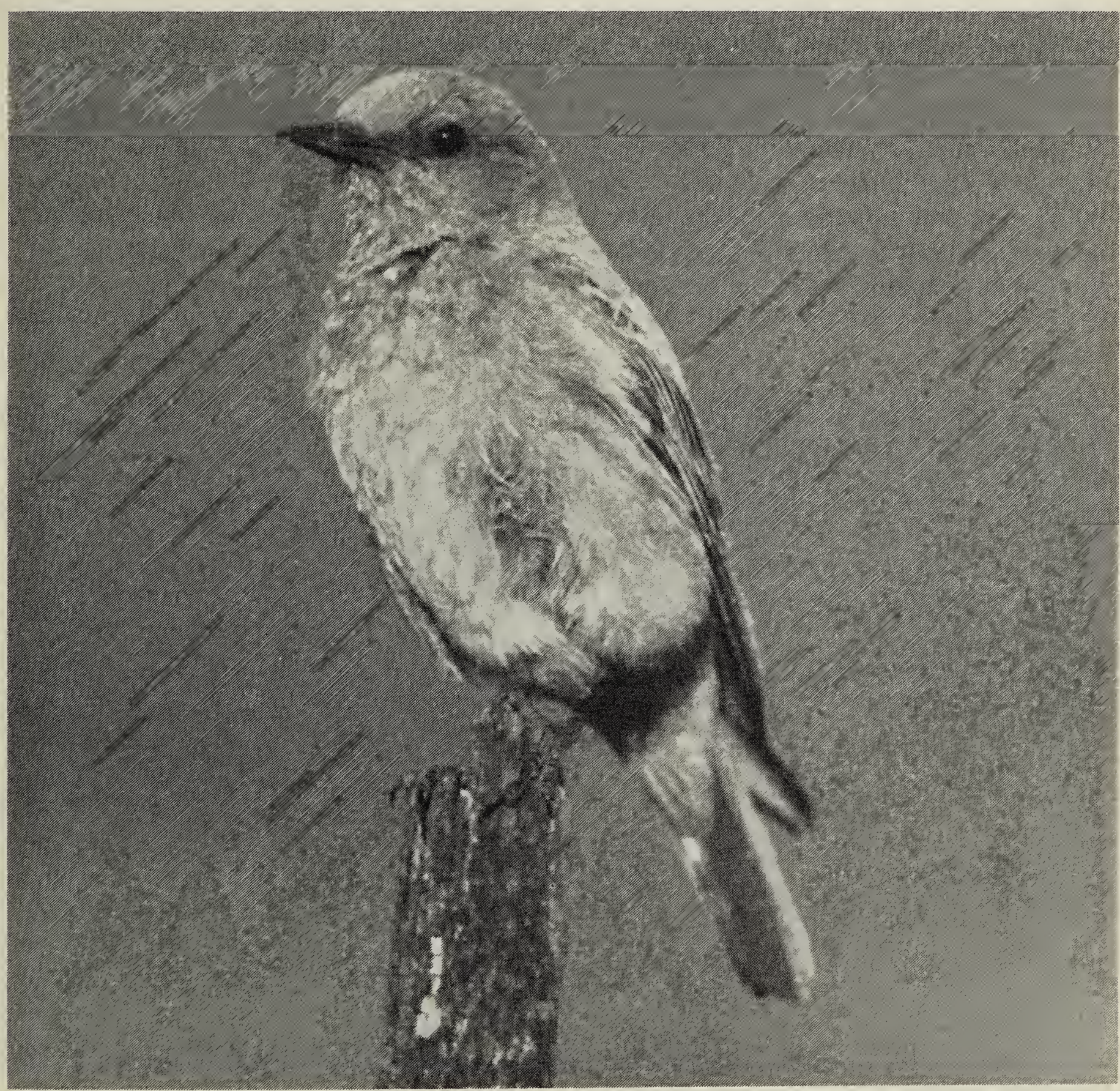

